\title{
From Waste Materials Skin-Friendly Nanostructured Products to Save Humans and the Environment
}

\author{
Pierfrancesco Morganti ${ }^{1,2,3}$, Yuan-Hong $\mathrm{Li}^{4}$ \\ ${ }^{1}$ Applied Cosmetic Dermatology, University of Naples, Naples, Italy; ${ }^{2}$ China Medical University, Shenyang, China; ${ }^{3} \mathrm{R} \& \mathrm{D}$ Centre of \\ Nanoscience Mavi Sud s.r.l, Aprilia, Italy; ${ }^{4}$ Department of Dermatology, No. 1 Hospital of China Medical University, Shenyang, China. \\ Email: morganti@iscd.it; info@mavicosmetics.it; morganti@mavicosmetics.it
}

Received May $18^{\text {th }}, 2011$; revised July $5^{\text {th }}, 2011$; accepted July $26^{\text {th }}, 2011$.

\begin{abstract}
Waste material from the fishing industry disposed off-shore exceeds 250 billion tons/year, and it is considered hazardous due to its high perishability and polluting effect, both on land and sea. Considering the actual production of chitin, chitosan and oligosaccharides from crustaceons, it is understandable how difficult it is to eliminate all the waste material obtained from food industry, therefore the need for more innovation and creativity. With this in mind we propose an industrial use of the natural chitin nanocrystals (known as chitin-nanofibrils-CN) to produce innovative cosmetics, food supplements and protective films that can improve our way of living while saving the environment.
\end{abstract}

Keywords: Waste, Chitin, Chitin Nanofibrils

\section{Introduction}

Terrestrial organisms, cultured and used on an industrial scale such as silkworms, honeybees and mushrooms, and the fishing industry produce considerable quantity of waste material, wound healing, bio-textiles, food coating, innovative cosmetics [1].

Thus, of the worldwide "chitin production estimated at about $10^{11}$ tons/year, about $25 \%$ remains accumulated as bio-waste [2], characterized by high perishability and polluting affect. In the sea this hazardous natural raw material rapidly leads to eutrophication exerting a high biochemical oxygen demand, while on land quickly becomes colonized by pathogens and spoilage organisms causing environmental and public health concerns [3-5].

Therefore, using this waste material to produce useful goods and obtain beneficial resources from its economical recycling has to be considered a must for our society, so interested in bettering the quality of life while respecting the environment.

It is interesting to underline the versatile biological activities this natural bio-saccharide and its derivatives possess. Due to their efficacy and safety as polymers of glucosamine and acetylglucosamine, they are used in the pharmaceutical, cosmetic, food, and textile industries.

These natural ingredients, normal components of the human body have, in fact, unusual multifunctional properties including, high tensile strength, interesting bioactivity, easy biodegradability, eco-biocompatibility; they are non-antigenic, and non-toxic, which favored their use in many applications [6,7] These qualities along with chitin's easy accessibility as a waste raw material and the necessity to transform this waste in high value-added products, makes it mandatory to increase the study of chitin to produce innovative, safe products capable of bettering human life while saving the environment. Today we already possess the ability to use chitin crystalline nanoparticles (known as, chitin nanofibrils or $\mathrm{CN}$ ) that naturally occur in chitinaceous waste raw materials $[8,9]$. These nano-structured fibers result in a larger surface area and a purer form in respect to the amorphous chitin powder present in the today market. Therefore the physical-chemical and biological qualities of this natural nano-sized polymer seems to be notably increased for its ability to form film, complexing-active ingredients, to chelate metal ions, and retain water, easily interacting with many biological structures at the molecular level $[10,11]$. Differently from the chitin powder and according to a newly patented easy process, in fact, many chemical and natural ingredients can be complexed by this crystal-like polysaccharide and then released into the 
skin/body, at appropriate sites and under certain conditions, without harmful side effects, possessing interesting new biological properties also [8-13].

For all these reasons these innovative pure nano-crystallites and their derivatives have been studied to verify their activity in many industrial and biomedical applications [14-18] (Figure 1).

$\mathrm{CN}$ and its derivatives, in fact, seem to be capable of eliciting both systemic and humoral human response, possessing the function of cell chemical-messenger, probably due to their capacity to activate by intercellular signals the skin cell's surface receptor proteins [19] (Figure 2). Further studies are necessary to better understand how the body's cells perceive these new nanostructured polymers and how they may affect the continuous communications among all the different skin cells, connecting them with the Nervous, Immune, Cutaneous and Endocrine Systems (N.I.C.E.) [20,21].

Some results obtained by the use of $\mathrm{CN}$ are reported to understand the many possibilities we have to produce

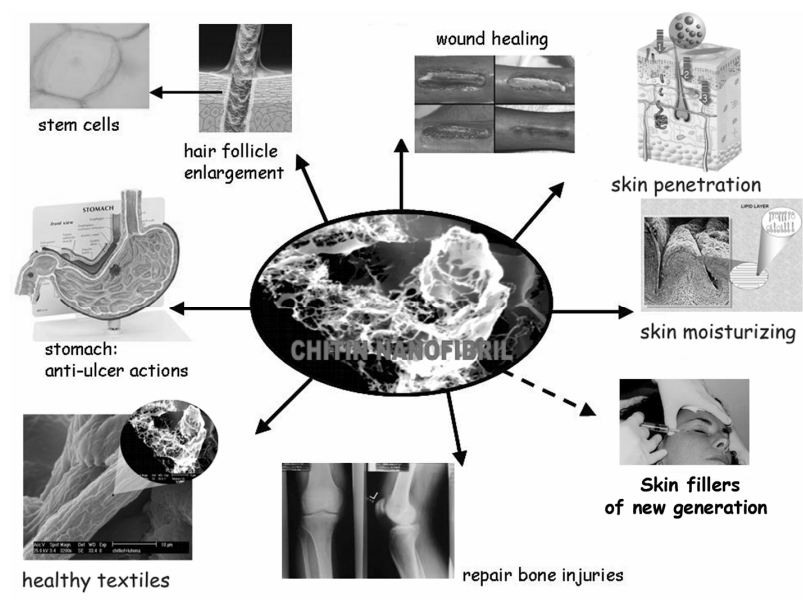

Figure 1. The many possible applications of chitin nanofibrils.

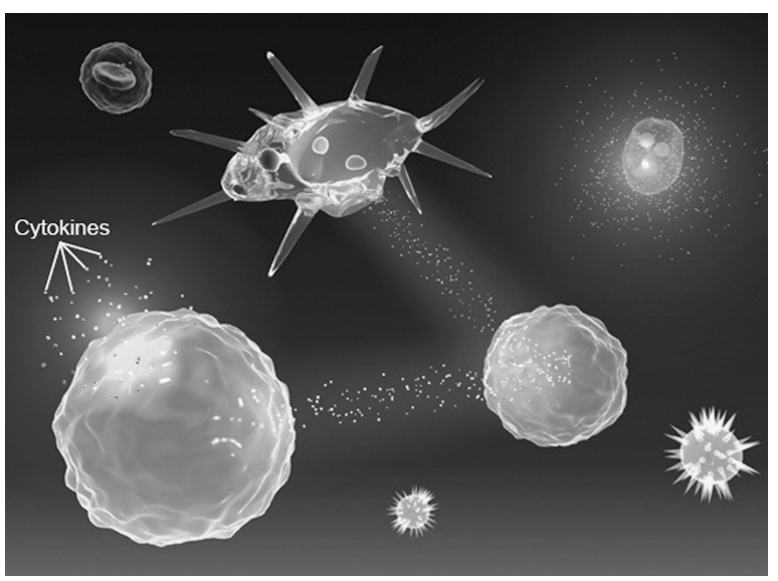

Figure 2. Intercellular signals. innovative goods eliminating part of the 250 billion tons/year of fisheries waste accumulating each year.

\section{Biomedical Application}

\subsection{Wound Healing and Anti-bacterial Activities}

For the well known effect of $\mathrm{N}$-acetyl-glucosamine to accelerate wound healing and the higher efficacy of its nanocrystal structure in comparison with the amorphous chitin, a gel containing $\mathrm{CN}$, complexed with clorexidine digluconate together with arginine and glycine, has shown to possesses an interesting cicatrizing and antiinflammatory activity, avoiding the formation of keloids and hypertrophic scars both in the short and long term. (Figure 3) [14-16]. This product quickly causes the alteration of the pathogenic micro-organisms membrane, while it promotes a better and regular collagen production (Figure 4).

Moreover complexing $\mathrm{CN}$ with lutein and mixing it with cellulose, it has been possible to obtain easily bio-

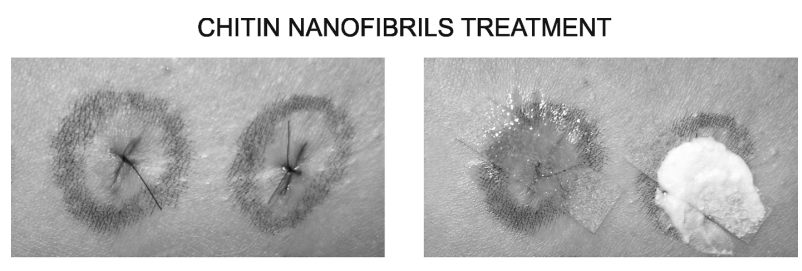

$a=$ control $b=$ active BEFORE

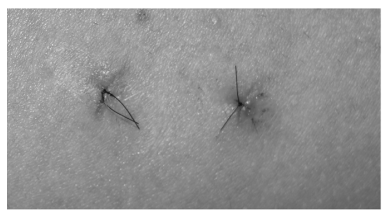

AFTER 15 days

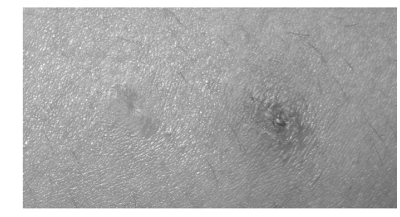

AFTER 30 days
Figure 3. The anti inflammatory and cicatrizing activity of a gel based on the use of chitin nanofibrils.

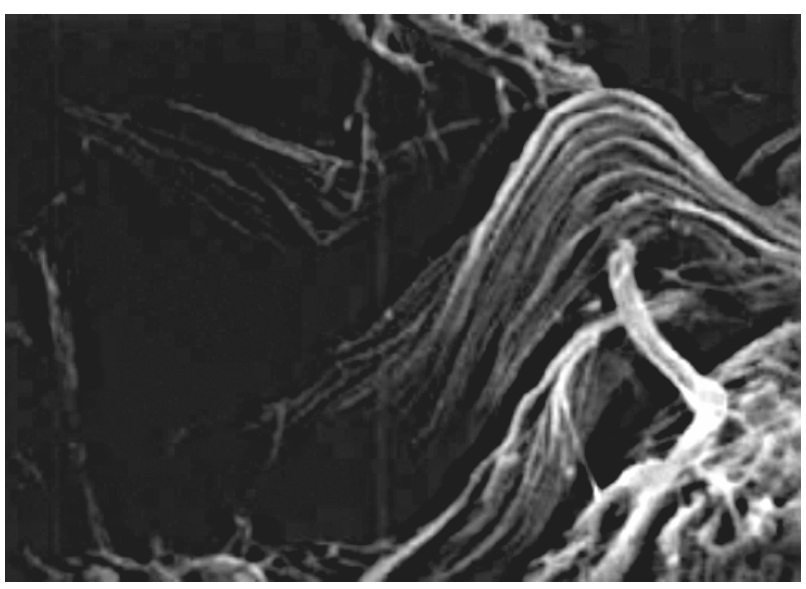

Figure 4. The regular collagen production promoted by chitin nanofibrils. 
degradable anti-UVA fibers and bio-textiles (Figures 5 and 6) [17], as well as to produce non woven tissue using nano-structured $\mathrm{Ag}^{+}$and electrospinning technologies [18] (Figure 7). What it is interesting to underline is the possibility to intimately incorporating $\mathrm{CN}$-lutein or $\mathrm{Ag}^{+}$either as a powder or as suspension in one of the process step preceding the spinning of the cellulose solution or the non-woven process. In this way lutein or $\mathrm{Ag}^{+}$remain firmly anchored in the fiber or nonwoven matrix being intimately distributed over the fiber cross-section. This methodology constitutes an important advantage comparated to the usual surface treatment available on the market. By this process $\mathrm{CN}$-lutein remains anchored into the core of the formed fiber and into the fabric structure when it is, for example, twisted and/or treated by the conventional cleansing methods. On the other hand, the nonwoven sheet incorporating the antimicrobial $\mathrm{Ag}^{+}$is in fact, effective in adsorbing exudates and allowing oxygen diffusion. According to Muzzarelli [22] and Hayashi [23] lysozyme, produced by macrophages, hydrolyzes chitin and its derivatives into oligomers, which activate the macrophages to produce nitric oxide, reactive oxygen species, tumor necrosis factor- $\alpha$, interferon, and interleukin-1 (IL-1). As a consequence, macrophages increase

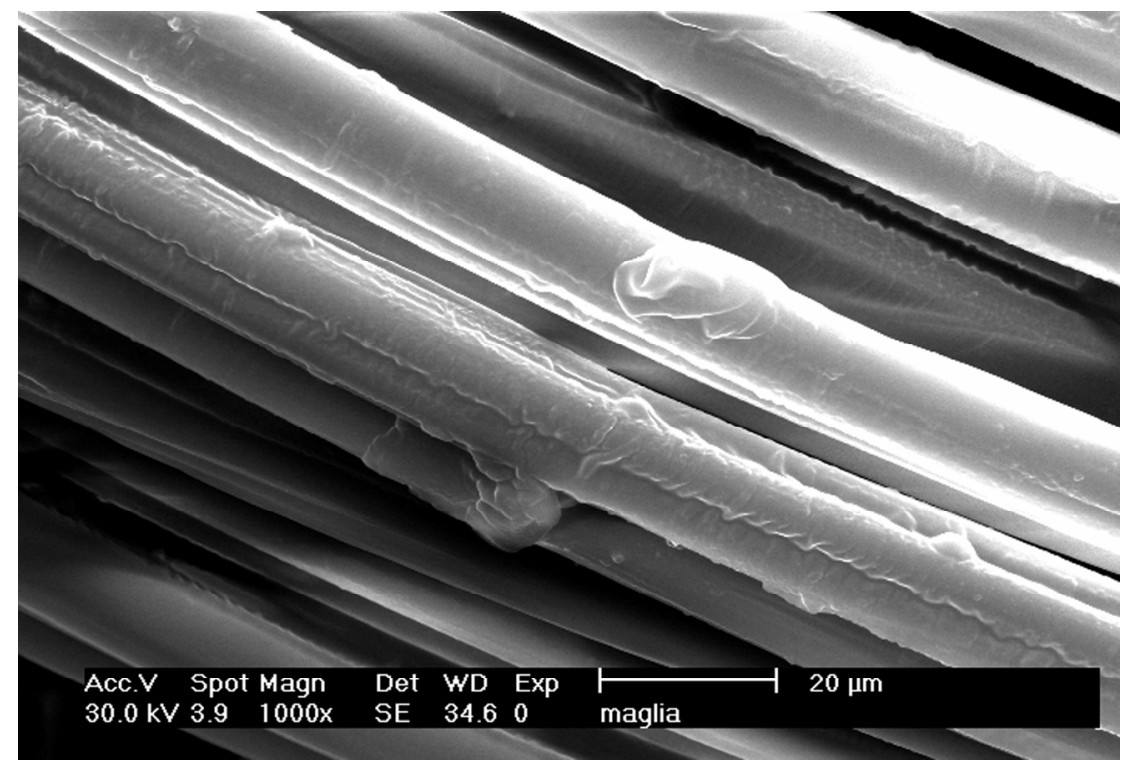

Figure 5. Fibres of cellulose and chitin nanofibrils complexed with lutein.

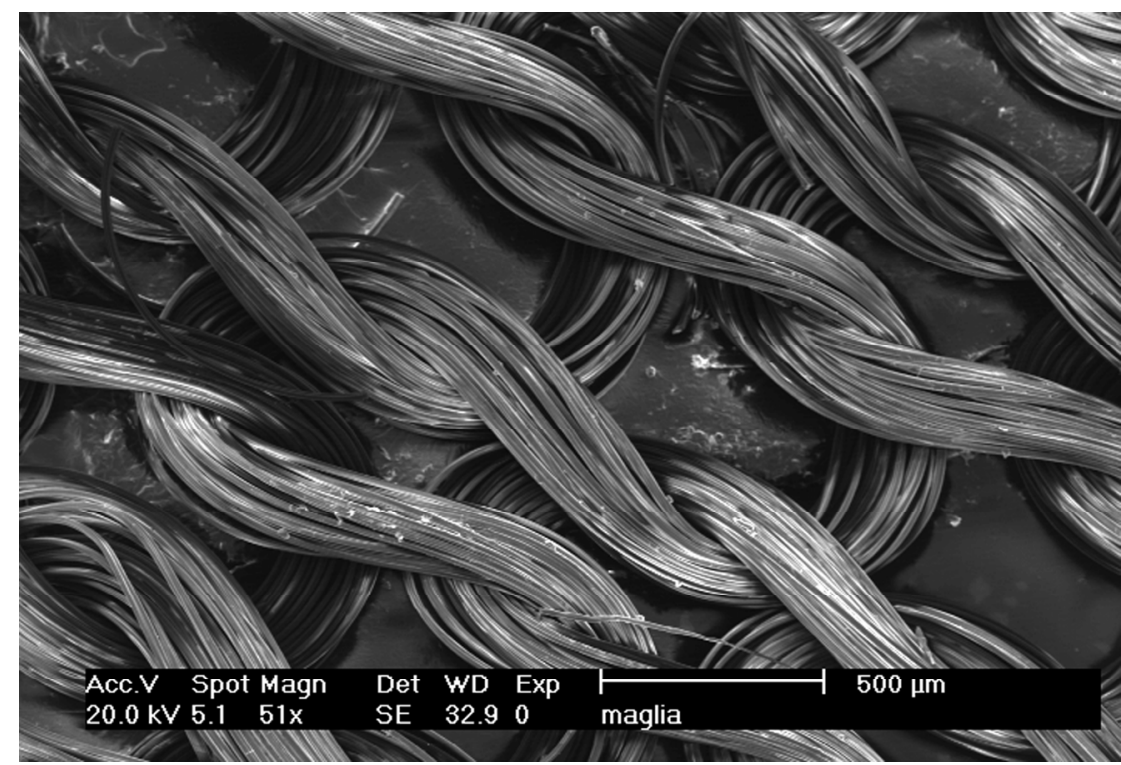

Figure 6. Bio-textile made by fibers of cellulose/chitin nanofibrils complexed. 


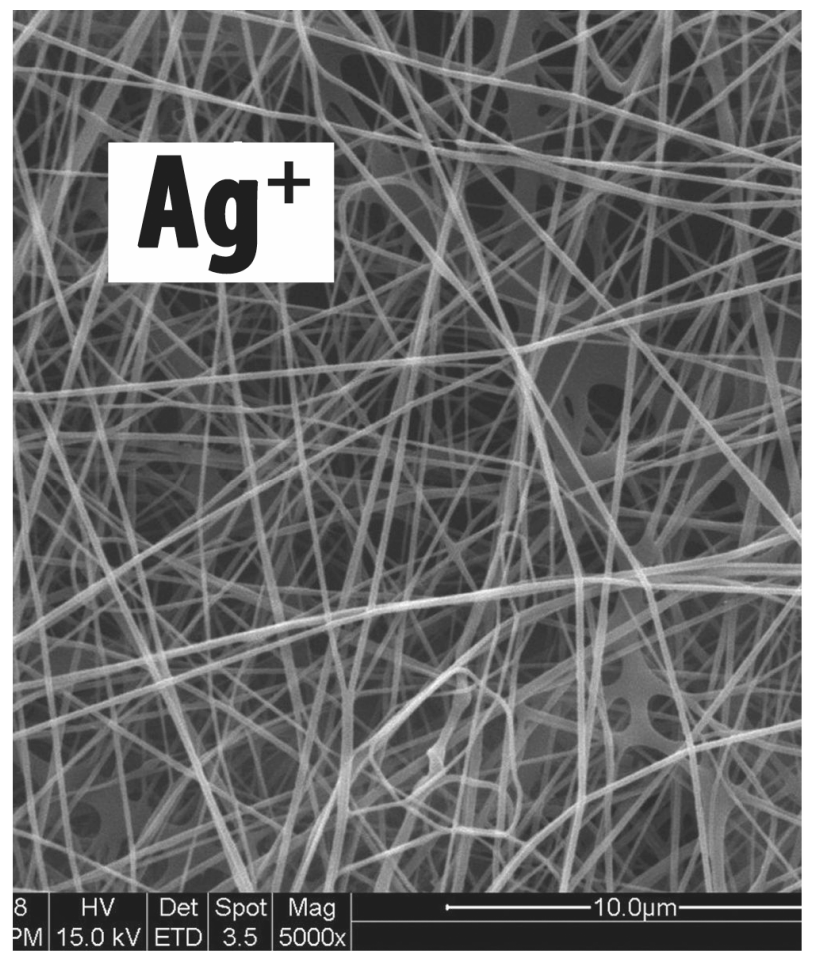

Figure 7. Non-woven tissue incorporating chitin nanofibrils complexed with $\mathrm{Ag}^{+}$.

their production of lysozyme, chitinase and N-acetyl$\beta$-D-glucosaminodase, which catalyze the total depolymerization to monomers. The monomeric aminosugars become available to the fibroblasts, which proliferate under the action of IL-1, for incorporation into chondroitin-4 and 6-sulfate, hyaluronan, and keratin sulfate, thus guiding the ordered deposition of collagen, influenced by chito-oligomers. During all these biological processes $\mathrm{CN}$ has shown to be more active than chitin today in use.

\subsection{Drug/Cosmetic Delivery Systems}

As previously seen, $\mathrm{CN}$ has the capacity to incorporate chemicals (drugs, cosmetic active ingredients, etc.) within its structure, successively releasing them by simple diffusion at the appropriate body site in function of the $\mathrm{CN}$-complex used, the specifically designed laboratory conditions in which the complex is formed, its biodegradability and bio-availability. The smaller the complex, the greater the degradation rate and bioavailability. Depending on the typology of the scaffold or the carrier, whether in the form of gel, fiber or porous matrix, the obtained CN-complex may be used for skin and mucous membrane hydration, bone regeneration, or for an antiaging or anti-acne cosmetic therapy [24-27]. Differently from chitin, $\mathrm{CN}$ and its complexes have shown the possibility to be used as active ingredients and carriers for many biomedical purposes. Thus, it has been shown that the $\mathrm{CN}$-lutein complex possesses an interesting activity as a stem-cell-stimulating compound, at the level of the hair bulb (Figure 8) [28]. In addition, the CN-antioxidant/immunomodulant complexes have shown great efficacy as anti-ageing agent (Figure 9) [29], while, the same complexes used by different carriers, improve skin conditions as mild to severe xerosis [30]. Moreover CN, complexed with nicotinamide and linoleic acid rich phosphatidyl-choline, increases the efficacy of anti-acne products [31] (Figure 10). Finally, other in-progress studies, based on the use of $\mathrm{CN}$ complexed with chitosan and/or $\mathrm{Ag}^{+}$, have shown the possibility to produce edible films and coatings to maintain and preserve food quality and texture (Figure 11) [32-34], using food-like rawmaterial, as well as to realize ultra-filtrating bio-membranes, capable of removing microorganisms with a possible use
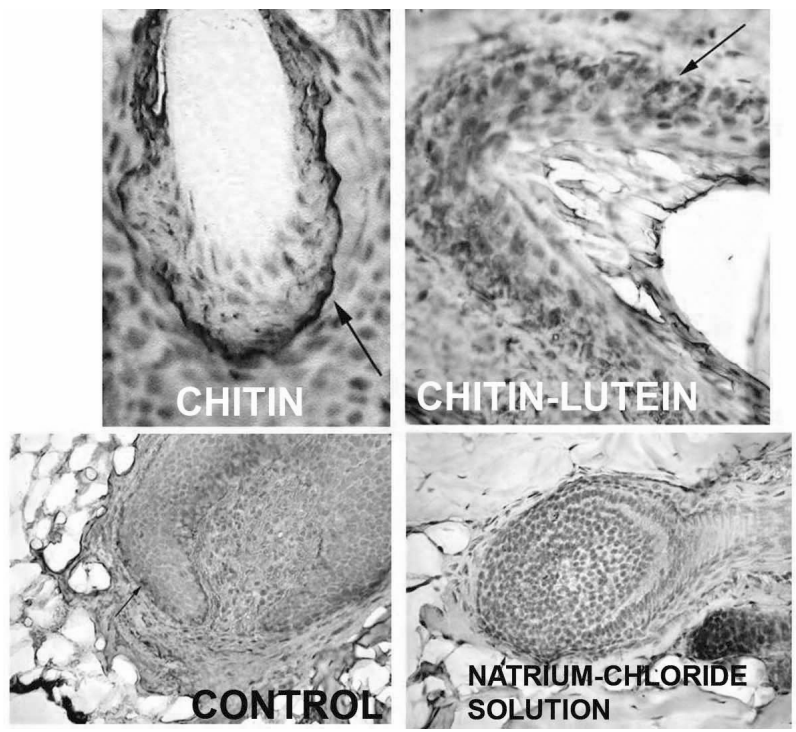

Figure 8.The stimulating activity on hair'stem cells of chitin nanofibrils complexed with lutein.

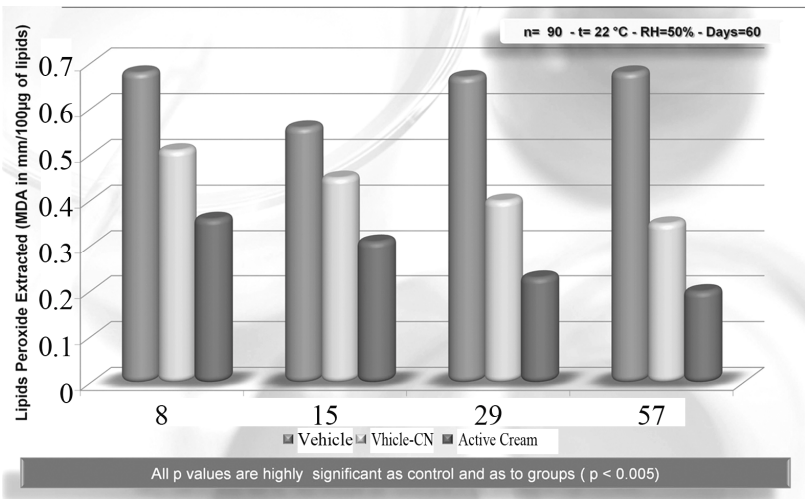

Figure 9. Activity of chitin nanofibrils alone or complexed with antioxidant and immunomodulant ingredients (active cream) vs vehicle on lipids peroxides of skin photoaged women. 


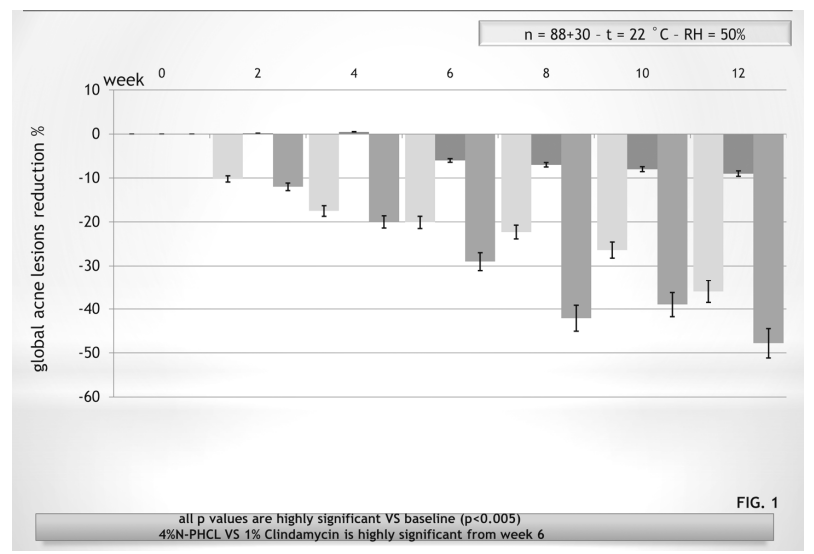

Figure 10. Mean reduction of the global acne lesions after a 12 week treatment by $4 \%$-nicotinamide phosphatidylcoline linoleic-rich emulsion vs 1\%-clindamicyn phosphate and the vehicle.

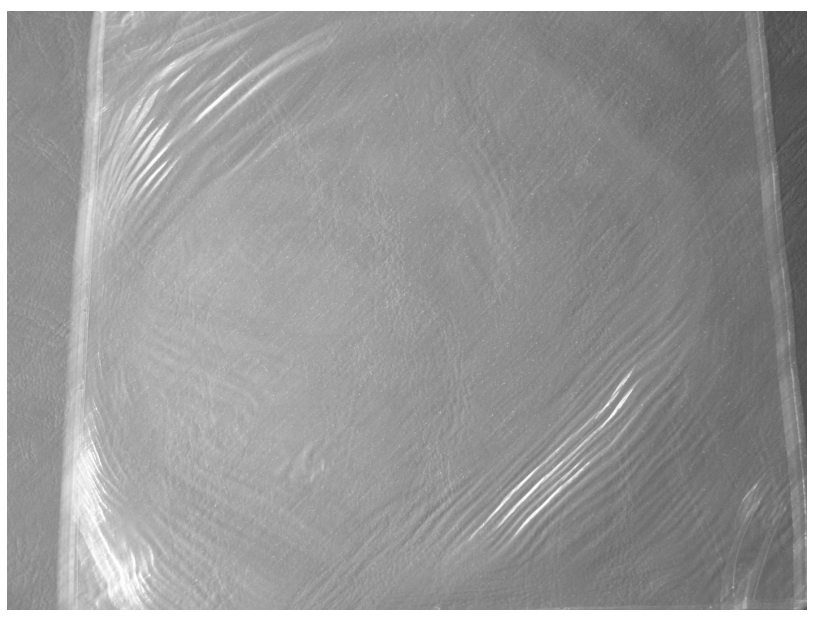

Figure 11. A protective and food coating film made of chitosan and chitin nanofibrils.

in treating waste water (Figure 12) [35].

In conclusion, $\mathrm{CN}$, recovered from waste material has been found to be an interesting natural biomaterial effective both for medical and non-medical applications. All its recovered specific properties have shown to be superior to those of the well known chitin-based oligosaccharide compounds. These ameliorated and powered activities recovered by the use of $\mathrm{CN}$ seem to be linked to its high purity and nano-sized crystal structure. Therefore it should be necessary to go on with other studies for all the possible and future uses of this interesting nanostructured polymer. It should be interesting, for example, to compare the activity of the synthetic polymeric films such as polyethylene and poly (ethyleneterephthalate) actually used from consumers to protect food, with the activity of the same films made of $\mathrm{CN}$ and its complexes, totally sure because made of edible pure and natural raw material. Moreover, the interesting biomedical activities of

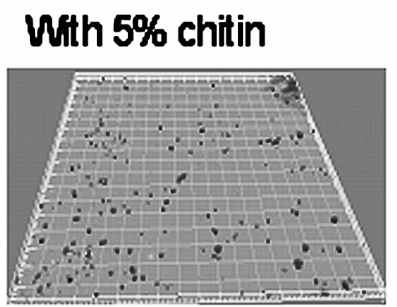

Without chitin
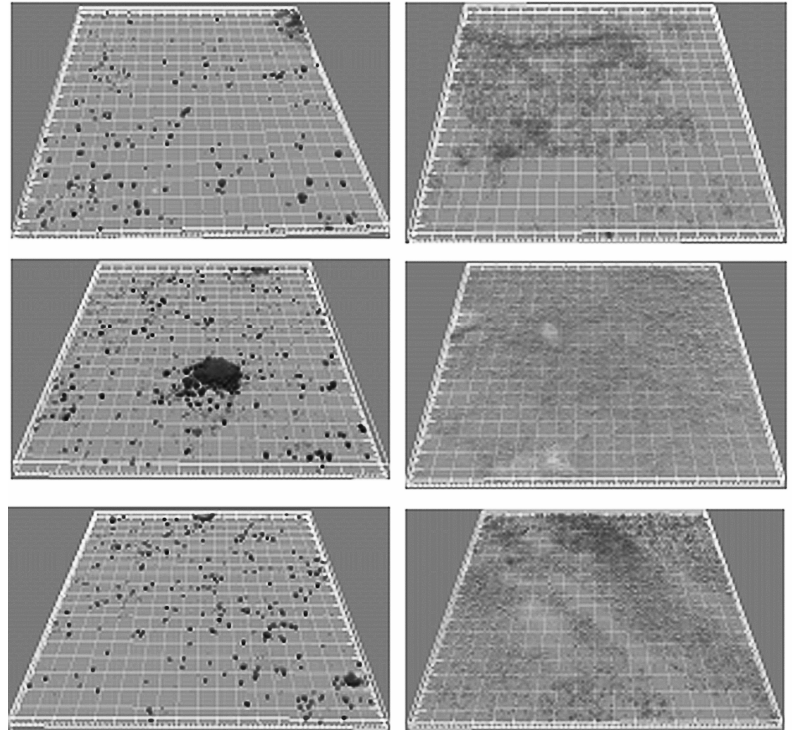

Figure 12. The black spots are killed microorganisms (on the left); the gray spots are reproducing microorganisms (on the right).

$\mathrm{CN}$ and pure polyglucosides obtainable from bio-waste accumulated materials are opening new possibilities to produce goods from innovative nanostructured active ingredients of new generation without impoverish our environment. Combining the high degradability and bioavailability of $\mathrm{CN}$, and understanding more fully all the properties and capacities this natural nanostructure should have to act at the human cellular level, it will be possible to find other interesting applications, unknown today, capable of improving our way of living.

Let us save the environment by the use of this natural ingredient which, obtainable from waste material, combines the activity of a natural compound with the efficacy of a nanostructured molecula.

\section{REFERENCES}

[1] N. New, T. Furuike and H. Tamura, "Chitin and Chitosan from Terrestrial Organisms,” In: S.-K. Kim, Ed., Chitin, Chitosan, Oligosaccharides and Their Derivatives, CRC Press, New York, 2011, pp. 3-10.

[2] FAOSTA, "FAO Statistical Databases, Fisheries Data," Food and Agriculture Organization of the United Nations, Rome, 2001. www.fao.org

[3] M. Healy, A. Green and A. Healy, "Bio-processing of Marine Crustacean Shell Waste," Acta Biotechnologica, Vol. 23, No. 2-3, 2003, pp. 151-160. doi:10.1002/abio.200390023

[4] M. Islam, S. Khan and M. Tanaka, "Waste Loading in Shrimp and Fish Processing Effluents: Potential Source of Hazards to the Coastal and Nearshore Environments," 
Marine Pollution Bulletin, Vol. 49, No. 1-2, 2004, pp. 103-110. doi:10.1016/j.marpolbul.2004.01.018

[5] W. M. Brück, J. W. Slater and B. F. Carney, "Chitin and Chitosan from Marine Organisms," In: S.-K. Kim, Ed., Chitin, Chitosan, Oligosaccharides and Their Derivatives, CRC Press, New York, 2011, pp. 11-23

[6] R. N. Tharanathan and F. S. Kittur, "Chitin-The Undisrupted Biomolecule of Great Potential," Critical Reviews in Food Science and Nutrition, Vol. 43, No. 1, 2003, pp. 61-87. doi:10.1080/10408690390826455

[7] J. K. Vidanarachchi, M. S. Kurukula Suriya and S.-K. Kim, "Chitin, Chitosan and Their Oligosaccharides," In: S.-K. Kim, Ed., Chitin, Chitosan, Oligosaccharides and Their Derivatives, CRC Press, New York, 2011, pp. 543-560

[8] P. Morganti, "Chitin-Nanofibrils in Skin Treatment," Journal of Applied Cosmetology, Vol. 27, 2009, pp. 251-270.

[9] P. Morganti, Y. H. Lee, and G. Morganti, "Nano-Structured Products: Technology and Future," Journal of Cosmetic Dermatology, Vol. 4, No. 3, 2008, pp. 253-260.

[10] P. Morganti, P. Del Ciotto, G. Morganti, V. Fabien-Soulé, "Application of Chitin Nanofibrils and Collagen of Marine Origin as Bioactive Ingredients," In: S.-K. Kim, Ed., Marine Cosmeceuticals: Latest Trends and Prospects, CRC Press, New York, 2010.

[11] P. Morganti, "Chitin Nanofibrils and Their Derivatives as Cosmecuticals," In: S.-K. Kim, Ed., Chitin, Chitosan, Oligosaccharides and Their Derivatives, CRC Press, New York, 2011, pp. 531-542.

[12] P. Morganti, H. D. Chen, H. H. Gao, Y. Li, C. Jacobson, J. Arct and W. Fabianowski, "Nanoscience Challenging Cosmetics, Healthy Food \& Biotextiles," Personal Care \& Cosmetics,Vol. 135, No. 4, 2009, pp. 32-41.

[13] MAVI Sud. PCT/IB2005/053576.

[14] R. A. A. Muzzarelli, P. Morganti, G. Morganti, P. Palombo, M. Palombo, G. Biagini, M. Mattioli Belmonte, F. Giantomassi, F. Orlandi and C. Muzzarelli, "Chitin Nanofibrils/Chitosan Composites as Wound Medicaments," Carbohydrate Polymers, Vol. 70, No. 3, 2007, pp. 274-284. doi:10.1016/i.carbpol.2007.04.008

[15] M. Mattioli-Belmonte, A. Zizzi, G. Lucarini, F. Giantomassi, G. Biagini, G. Tucci, F. Orlando, M. Provinciali, F. Carezzi and P. Morganti, "Chitosan-linked to chitosan glycolate as Spray, Gel, and Gauze Preparations for Wound Repair," Journal of Bioactive and Compatible Polymers, Vol. 22, No. 5, 2007, pp. 525-538. doi:10.1177/0883911507082157

[16] P. Mezzana, "Clinical Efficacy of a New Chitin-Nanofibrils Based Gel in Wound Healing," Acta Chirurgiae Plasticae, Vol. 50, No. 3, 2008, pp. 81-84.

[17] P. Morganti and P. Gioia, "Studies on Bio-Textiles Activity," 2010, unpublished data.

[18] P. Morganti and M. Palombo, "A Cicatrizing Activity of a Novel-Gel Based on the Use of Chitin-Nanofibrils in the Short and Long Period," Journal of Applied Cosme- tology, 2011, in print.

[19] S. P. Vys, R. Paliwal and S. R. Paliwal, "Chitosan/Chitosan Derivatives as Carriers and Immunoadjuvants in Vaccine Delivery," In: S.-K. Kim, Ed., Chitin, Chitosan, oligosaccharides and Their Derivatives, CRC Press, New York, 2010, pp. 339-356. doi:10.1201/EBK1439816035-c25

[20] P. Morganti, Y.-H. Li and H.-D. Chen, "NICE Melody for Innovative Mind-Body Skin Care," Cosmetic Science Technology, Vol. 21, 2011, pp. 49-59.

[21] P. Morganti and H.-D. Chen, "Skin Life and Cell Management: The NICE Approach," Personal Care, Vol. 4, No. 1, 2011, pp. 29-36.

[22] R. A. A. Muzzarelli, "Human Enzymatic Activities Related to the Therapeutic Administration of Chitin Derivatives," Cellular and Molecular Life Sciences, Vol. 53, 1997, pp. 267-276.

[23] Y. Hayashi, "Applications of Chitosan Oligosaccharide and Glucosamine in Dentistry," In: S.-K. Kim, Ed., Chitin, Chitosan, Oligosaccharides and Their Derivatives, CRC Press, New York, 2011, pp. 447-460.

[24] P. Morganti, G. Morganti, G. Fabrizi and A. Cardillo, "A New Sun to Rejuvenate the Skin," Journal of Applied Cosmetology, Vol. 26, No. 4, 2008, pp. 159-168.

[25] F. S. Madonna Terracina, G. Novelli and M. Valeriani, "BI.LA.P (Biostimulation Laser Peeling): Multidrugs Biostimulation and Erbium: Yag Superficial Laser Peeling. A New Technique to Treat Moderate Photodamaged Skin," Journal of Applied Cosmetology, Vol. 26, No. 4, 2008, pp. 169-178.

[26] P. Morganti, M. Palombo, P. Palombo, G. Fabrizi, A. Cardillo, F. Carezzi, G. Morganti, E. Ruocco, S. Dziergowski, "Cosmetic Science in Skin Aging: Achieving the Efficacy by the Chitin Nano-Structured Crystallites," SOFW-Journal, Vol. 136, No. 3, 2010, pp. 14-24.

[27] P. Morganti, "Chitin Nanofibrils for Cosmetic," Cosmetics and Toiletries USA Edition, Vol. 125, No. 4, 2010, pp. 36-39.

[28] G. Biagini, A. Zizzi, F. Giantomassi, F. Orlando, G. Lucarini, M. Mattioli Belmonte, M. G. Tucci and P. Morganti, "Cutaneous Absorption of Nanostructured Chitin Associated with Natural Synergistic Molecules (Lutein)," Journal of Applied Cosmetology, Vol. 26, No. 2, 2008, pp. 69-80.

[29] P. Morganti, G. Fabrizi, M.Palombo, F. Guarneri, A. Cardillo and G. Morganti, "New Chitin Complexes and Their Anti-aging Activity from Inside out," The Journal of Nutrition Health and Aging, 2011, in print.

[30] P. Morganti, G. Fabrizi, F. Guarneri, M. Palombo, P. Palombo, A. Cardillo, E. Ruocco, P. Del Ciotto and G. Morganti, "Repair Activity of Skin Barrier by ChitinNanofibrils Complexes," Söfw Journal, 2011, in print.

[31] P. Morganti, E. Berardesca, B. Guarneri, F. Guarneri, G. Fabrizi, P. Palombo and M. Palombo, "Topical Clindamicyn $1 \%$ vs Phosphatidylcholine Linoleic Acid-Rich and Nicotinamide 4\% in the Treatment of Acne: A Multicenter-Randomized Trial," International Journal of Cosmetic Science, Vol. 33, 2011, pp. 1-10. 
[32] P. Morganti, "Chitin Nanofibrils in Textiles," Speciality Chemicals Magazine, Vol. 28, No. 9, 2008, p. 26.

[33] G. Tishchenko, J. Peter, E. Pavlová, J. Brus, M. Netopilík, M. Pekárek, Z. Sedláková, E. Y. Rosova, M. Smirnov and G. K. Elyashevich, "Chitin Whisker-Reinforced Chitosan Films Formed under Applied Electric Field," The 4th Visegrad Conference on Membrane Science and Technology, Prague, 7-11 June 2009, p. 156.

[34] G. Tishchenko, J. Peter, E. Pavlová, J. Brus, M. Netopilík,
M. Pekárek, Z. Sedláková, E. Y. Rosova, M. Smirnov and G. K. Elyashevich, "Effect of Applied Electric Field on Structure and Permeability of Chitin Whiskers-Reinforced Chitosan Membranes," 73rd Prague Meeting on Macromolecules, Praha, 5-9 July 2009, p. 137.

[35] A. Chianese, M. Stoller, J. Haack, W. Opaka and P. Morganti, "Bactericidal Activity of Chitin/Chitosan Based Water-Filters," 2010, unpublished data. 